\title{
EFFECT OF ECCENTRICITY IN SANDY SLOPE OF LATERALLY LOADED SINGLE PILE
}

\author{
SIVAPRIYA, S.V..$^{1, *}$, BALAMURUKAN, R. ${ }^{1}$, JAI VIGNESHWAR, A. ${ }^{1}$, PRATHIBHA \\ DEVI, N. ${ }^{1}$, SHRINIDHI, A. ${ }^{1}$ \\ ${ }^{1}$ Department of Civil Engineering, SSN College of Engineering, Kalavakkam, Chennai, India 603110. \\ * corresponding author: sivapriyavijay@gmail.com.
}

\begin{abstract}
An experimental study was proposed to understand the behaviour of single pile in sloping ground with various eccentricity. Cohesionless soil was used for conducting experiments with a horizontal ground and with a slope of $1 \mathrm{~V}: 2 \mathrm{H}$. With calculated stiffness factor (T) as 92 $\mathrm{mm}$, the eccentricity was varied as $0 \mathrm{~T}, 0.5 \mathrm{~T}$ and $1 \mathrm{~T}$. The lateral capacity of the pile in horizontal and sloping ground condition decreases with increase in eccentricity; the increase in lateral capacity was linear too. The bending moment increases with increase in load; but the depth of maximum bending moment was $0.15 \mathrm{~m}$ for $0 \mathrm{~T}$ and $0.5 \mathrm{~T}$ of eccentricity. For $1 \mathrm{~T}$ of eccentricity, the depth of maximum bending moment varied to $0.07 \mathrm{~m}$ from the point of load. An equation was proposed to calculate the maximum bending moment of the pile for any eccentricity for a slope of $1 \mathrm{~V}: 2 \mathrm{H}$, which is the governing factor for pile designing.
\end{abstract}

\section{Keywords:}

Sloping ground; Lateral load;

Bending moment;

Maximum bending moment;

Eccentricity.

\section{Introduction}

Pile foundations are used to resist loads of structures in situations where the soil available at shallow depth is poor and there is a restriction on the settlement. Large structures such as chimneys, towers, water tanks, multi-storied buildings, retaining walls, bridge abutments, piers, fenders, dolphins, anchors for bulkheads and water front structures are subjected to the combined action of axial and lateral loads which is supported mainly on pile foundation. The lateral load can also occur due to scour. Soil-structure interaction is the mechanism that governs pile response behaviour and capacity of the structure to the applied loads.

The behaviour of laterally loaded pile depends upon the diameter, depth of embedment and soil stiffness under similar density [1]. The ultimate capacity of the pile and movement of the pile head under the design load are the two aspects considered in the laterally loaded piles; bending moment of the pile element for a given load is important because the foundation will fail upon inadequate stability [2]. While designing laterally loaded pile, soil- structure interaction should be considered to simulate the non-linear behaviour of the loaded soil [3]. A non-dimensional method was proposed by considering the stiffness, deformation, soil resistance and pile diameter by comparing all the existing method available to calculate the p-y curve method [4]. When considering the initial modulus of soilstructure interaction, the diameter of the pile has no effect on it [5]. Ultimate lateral resistance formed in front of the pile and side was calculated by introducing shape factor to account for the non-uniform distribution of earth pressure in front of the pile and lateral shear drag in formulae suggested by Fleming et al. [6, 7].

Incase of pile rested on a slope, it suffers additional load due to earth pressure. The behaviour of laterally loaded pile in small slope say 11 degree, the behaviour is similar to the horizontal ground condition; upon increase in $L / D$ ratio $(L$ - depth of embedment and $D$-diameter of the pile) for large slope angle (till $45 \mathrm{deg}$ ) the lateral capacity increases [8]. With increase in slope, below the critical depth the ultimate load is observed as same as that of horizontal ground [9]. With increase in slope angle, the ultimate lateral load capacity of the pile decreases due to the reduction in passive wedge formed in front of the pile [10-12]. For a constant diameter, with increase in length of the pile the 
ultimate capacity increases. It was inferred that the pile is located 5 times the diameter of the pile from the slope crest, the effect of slope was negligible [13]. A multiplying constant was introduced in the classic p-y curve method to understand the behaviour of pile in and near the crest of sloping ground [14].

With increase in need of laterally loaded pile study in sloping ground with different eccentricity, an experimental study was proposed in the laboratory to understand the same when the pile is placed in the stable slope crest.

\section{Methodology}

In the current study, the pile in the horizontal ground was initially studied. Further, upon increasing the soil slope to $1 \mathrm{~V}: 2 \mathrm{H}$, a laboratory study was conducted with varying eccentricity.

\subsection{Soil and pile}

The soil used in the experiments was collected from Thiruporur area, Chennai, India. The soil posed a specific gravity of 2.65 [15]: it had $6 \%, 72 \%$ and $22 \%$ of coarse, medium and fine sand respectively. The co-efficient of uniformity and co-efficient of curvature were found as 2.18 and 0.88 [16] and the soil was graded as poorly graded sand (SP).

With a height of fall as $25 \mathrm{~cm}$, the obtained relative density was $70 \%$ [17], with angle of internal friction $32^{\circ}[18]$. Upon filling the tank with sandy soil, pile was installed in the desired position by simulating driven pile condition.

A hollow Aluminium pipe was modelled as pile with bottom plugged with inner diameter of 14 $\mathrm{mm}$ and outer diameter of $16 \mathrm{~mm}$ using Buckiham $n$ theorem for a concrete pile of diameter $0.3 \mathrm{~m}$ and length of $9 \mathrm{~m}$; the compressive strength of the pile is considered as M30 grade. A scaling factor of 20 is adopted [19].

\subsection{Sample preparation and parametric study}

The soil was filled in the tank of $1 \times 1 \times 0.5 \mathrm{~m}$ by rain-fall technique for the above said condition with hopper and cone arrangement [12]. Fig. 1 shows the test set-up of laterally loaded pile in sloping ground. The tank was free from side wall effect. The deformation of the pile was measured using LVDT place at the pile head and the bending moment was measured using strain gauges pasted along the length of the pile at an interval of $0.01 L, 0.3 L, 0.7 L$ and $0.9 L$ from the pile head. Strain gauge constant was found to be $0.0278 \mathrm{~N}-\mathrm{m} / \mu$ strain. This strain constant was multiplied with the obtained stain reading from the strain gauge read through the data acquisition system connected to the computer.

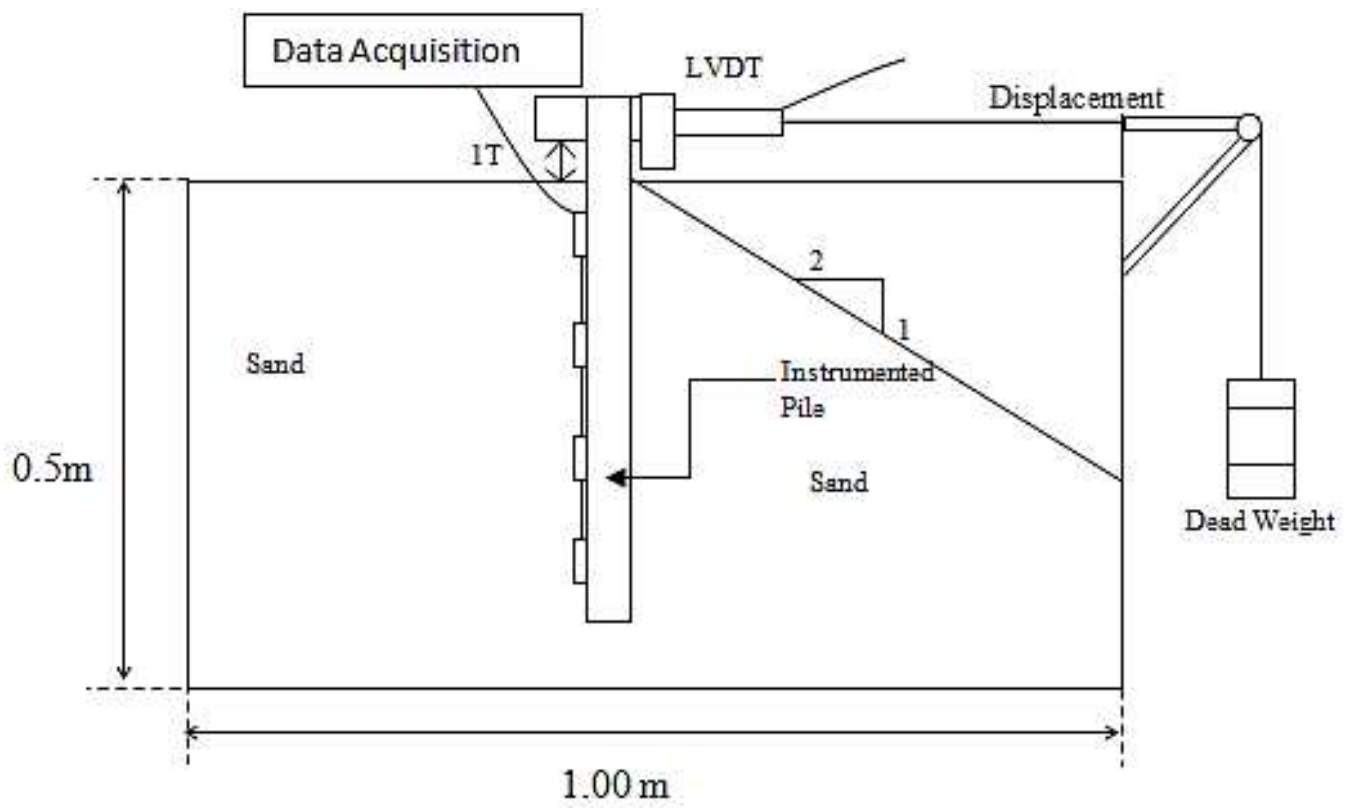

a/ Schematic representation of the test set up. 


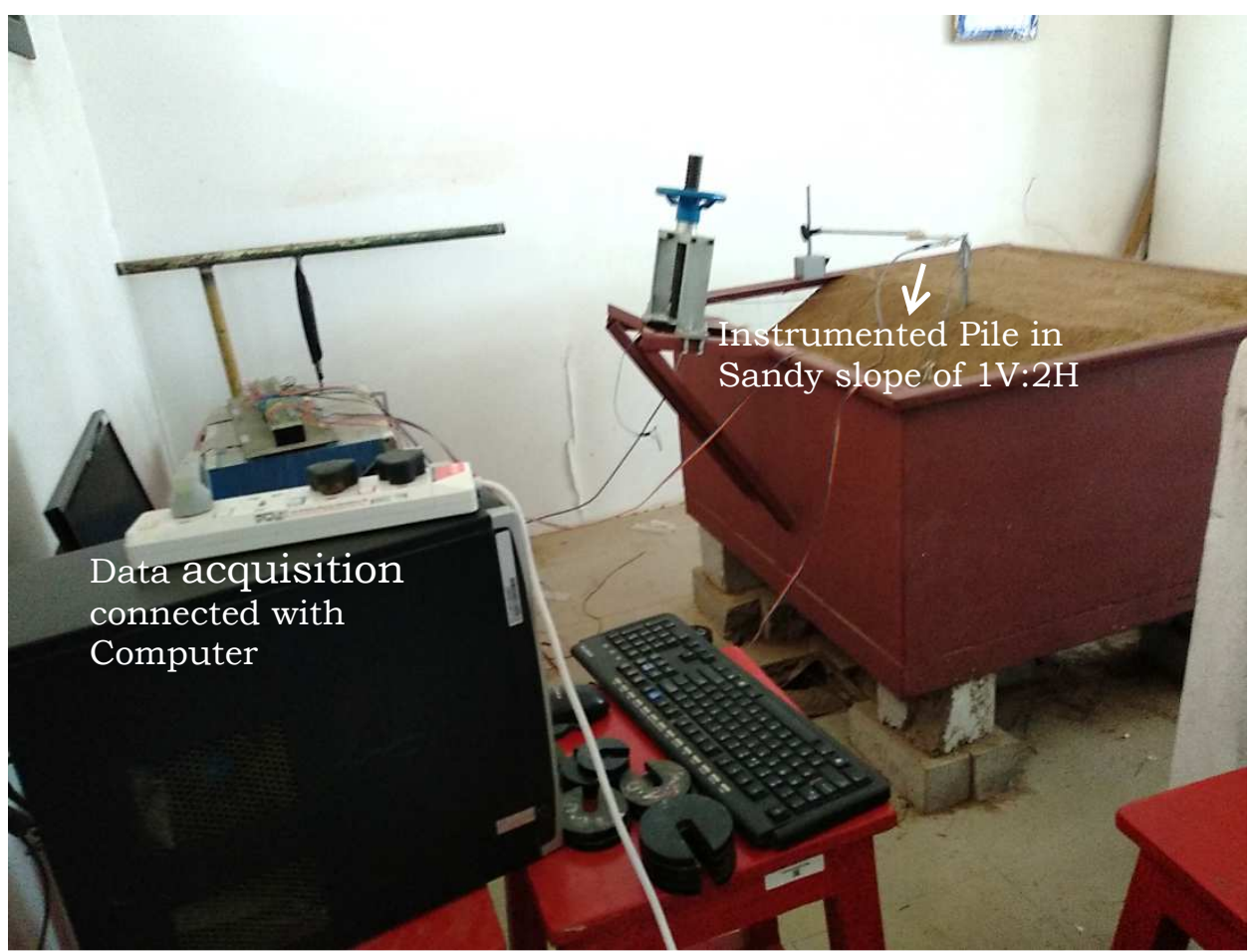

b/ Test set up in the laboratory.

Fig. 1: Test set-up laterally loaded pile.

The soil was filled in the tank for two ground conditions: horizontal (SO) and with a slope of $1 \mathrm{~V}: 2 \mathrm{H}(\mathrm{S} 1)$. Experiments were also conducted by varying the eccentricity of the pile in the slope crest. The eccentricity or the free head length was varied with respect to the stiffness factor $T$. Free head length was taken as $0 \mathrm{~T}(\mathrm{E} 0), 0.5 \mathrm{~T}(\mathrm{E} 1)$ and $1 \mathrm{~T}(\mathrm{E} 2)$ for a slope of $1 \mathrm{~V}: 2 \mathrm{H}$ from the crest level.

\section{Results and discussion}

An ultimate lateral load was considered as the load corresponding to displacement equivalent to $20 \%$ diameter of the pile [20]. Initial test was carried by keeping the ground horizontal and the stiffness factor was found using the formula:

$y=A_{y} \frac{H T^{3}}{E I}$.

From a known load $(\mathrm{H})$ and its corresponding displacement(y) for a flexural rigidity $E I$ of $93.1 \times 10^{6} \mathrm{Nmm}^{2}$ with constant $A_{y}$ as 2.42 , the stiffness factor - $T$ was found to be $92 \mathrm{~mm}$.

\subsection{Load - displacement behaviour}

For a horizontal ground, with the full length of pile embedded in the soil (with zero eccentricity) tests were conducted. The lateral capacity of the pile was calculated theoretically, the loads were added with an increment of $10 \%$ and the displacement reading was taken at the end of 30 minutes before applying the next load [21]. Fig. 2 shows the load-displacement behaviour of the pile in horizontal ground with $0,0.5$ and $1 \mathrm{~T}$ of eccentricity. For no eccentricity length, the lateral capacity of the pile kept on increasing with the addition of load linearly. The lateral capacity corresponding to $3.2 \mathrm{~mm}$ (displacement equal to $20 \%$ diameter of pile) displacement was found as $6.19 \mathrm{~N}$ in the horizontal ground with no eccentricity. The initial modulus of the soil - pile interaction was calculated as $2 \mathrm{~N} / \mathrm{mm}$. With increasing the free head to $0.5 \mathrm{~T}(46 \mathrm{~mm})$, the lateral capacity was found to be $3.97 \mathrm{~N}$ : this shows a reduction in the capacity by $35.86 \%$. For an embedded depth of $1 \mathrm{~T}$, the capacity was $3.78 \mathrm{~N}$ and shows a reduction to $38.93 \%$. For 0.5 and $1 \mathrm{~T}$ of eccentricity - free head, the modulus was calculated as 1.2 and $1.11 \mathrm{~N} / \mathrm{mm}$ respectively. With the increase in free head length, the rigidity of the pile embedded in the soil got reduced and this leads to a reduction in the capacity of the pile with an increase in free head length. 
In a sloping ground, the lateral capacity reduces due to a reduction in the passive pressure (Fig. 3). When the pile was kept at a crest of the slope with no eccentricity length, the lateral capacity was observed as $4.47 \mathrm{~N}$. When compared to the horizontal ground condition there was a reduction in capacity about $27.88 \%$. Similar to the horizontal ground condition, there was a linear increase in capacity with the addition of load $(R 2=0.9879)$. Modulus of the soil was calculated as $1.15 \mathrm{~N} / \mathrm{mm}$, which showed a reduction in modulus by $42 \%$ (almost $50 \%$ reduction has happened). The lateral capacity of $0.5 \mathrm{~T}$ and ' $1 \mathrm{~T}$ ' eccentricity was found $3.6 \mathrm{~N}$ and $2.82 \mathrm{~N}$ respectively; reduction in capacity was observed as 10.3 and $34.04 \%$ compared with the horizontal condition for the same eccentricity. While comparing the modulus of the soil for $0.5 \mathrm{~T}$ and $1 \mathrm{~T}$, it was noted as 1 and $0.875 \mathrm{~N} / \mathrm{mm}$ respectively. With an increase in eccentricity pile length, reduction in modulus ranged from 16 to $20 \%$ : this reduction was mainly due to the reduction in the volume of passive wedged soil.

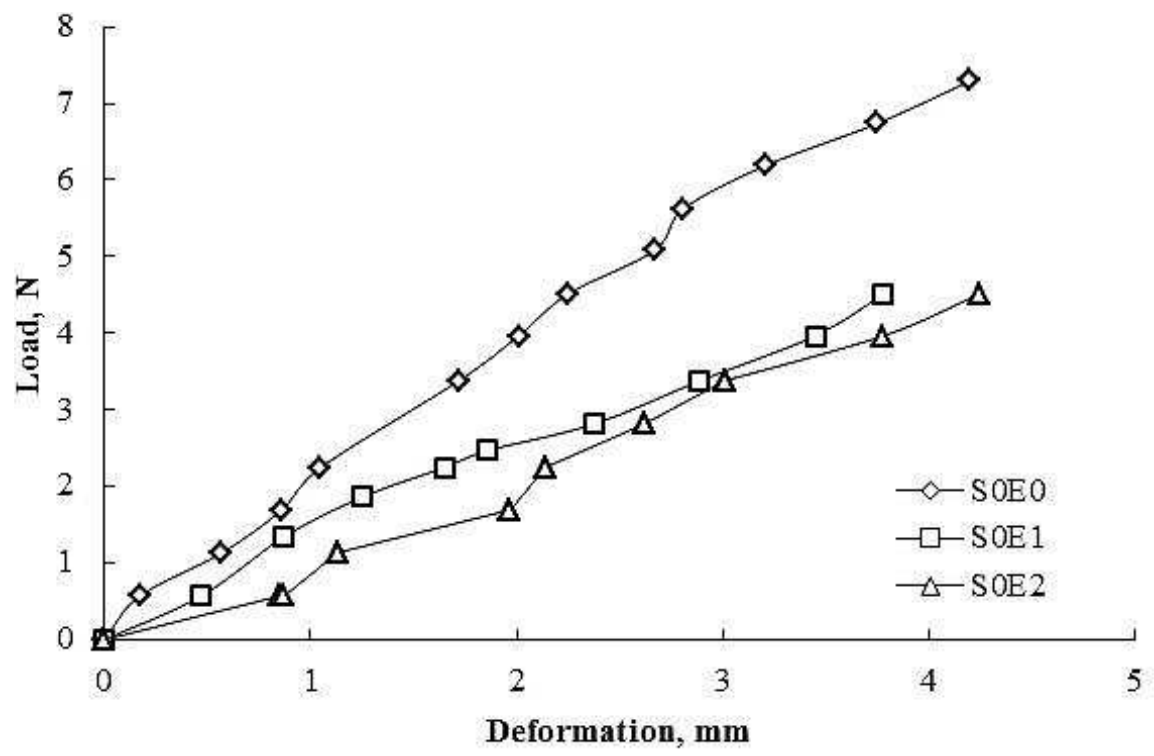

Fig. 2: Load-displacement behaviour of pile in horizontal ground.

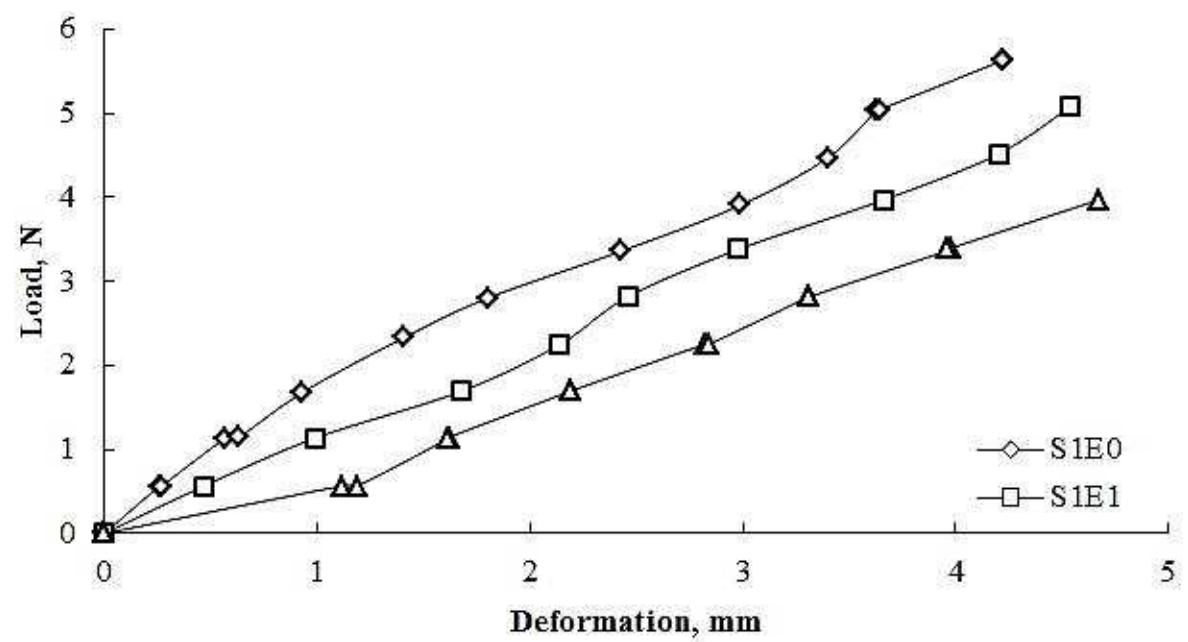

Fig. 3: Load-displacement behaviour of pile in sloping ground.

While comparing the ultimate lateral load of the pile for various stiffness factor and soil slope angle, there is a sudden reduction in capacity of the pile at $0.5 \mathrm{~T}$ when compared to $0 \mathrm{~T}$ for both the soil slope conditions (Fig. 4). When the pile was lifted from the ground level to $T$, the reduction in capacity was minimal. In the horizontal ground, the reduction in capacity of the pile, placed at 0.5 and $1 \mathrm{~T}$ was almost the same ( $3.97 \mathrm{~N}$ and $3.78 \mathrm{~N})$. But for the sloping ground, the reduction in capacity was linear $\left(R^{2}=0.97\right)$. In the sloping ground, the lateral capacity was influenced by both the eccentricity and the passive wedge. Hence the ultimate capacity of the pile in slope was lower than the pile at the horizontal ground. 


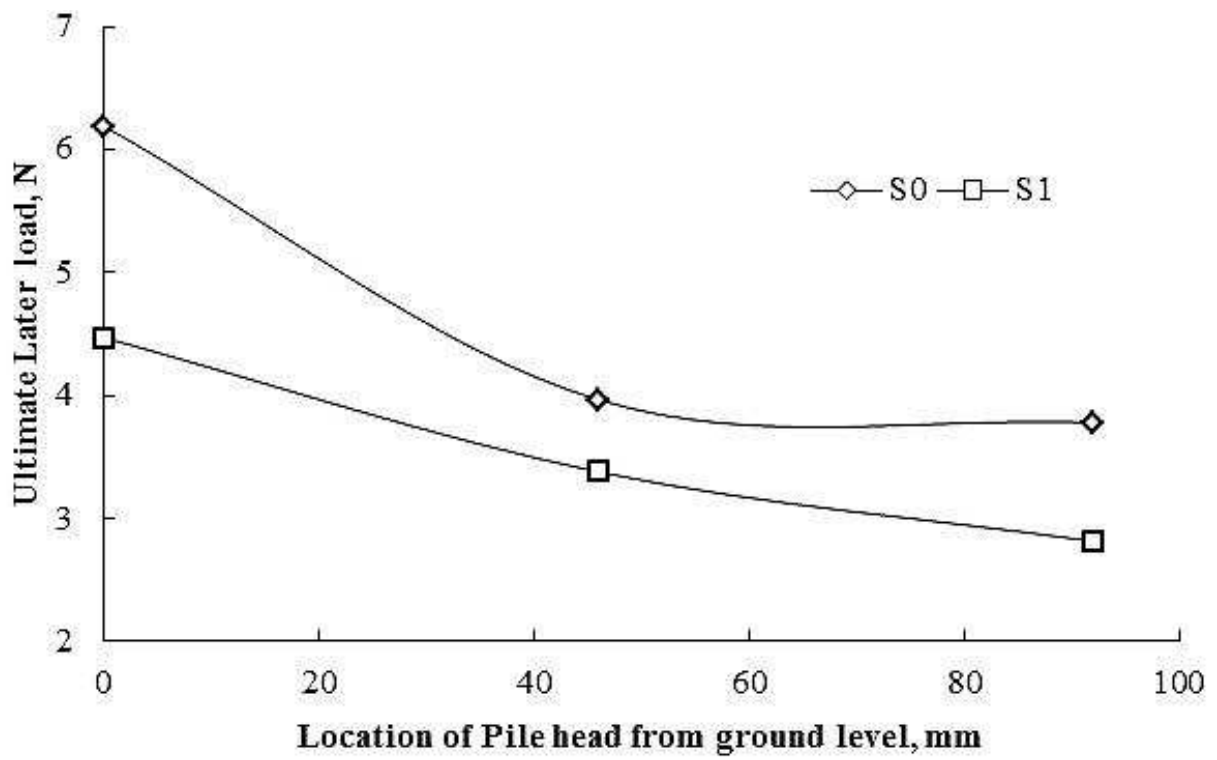

Fig. 4: Ultimate Lateral Load for varying slope and stiffness factor.

However, from the Figure 3 and 4 the load-displacement curve didn't become flat which showed the increase in displacement with respect to load; as the ultimate load was calculated corresponding to the displacement at pile head the experiment was terminated beyond it had yielded.

\subsection{Bending moment behaviour}

The bending moment of the pile was measured using the strain gauges pasted along the length of the pile for the applied load.

In a horizontal ground, with an increase in lateral load, the bending moment increases under embedded conditions. From Fig. 5, it was clearly visible that the behaviour of the pile was flexible in nature. The bending moment was observed as zero at the point of load application. The maximum bending was observed at a depth of 0.3 times the length of the pile (Fig. 6). There was a sudden increase in bending moment for $33.17 \mathrm{~N}$ because of the previous loading.

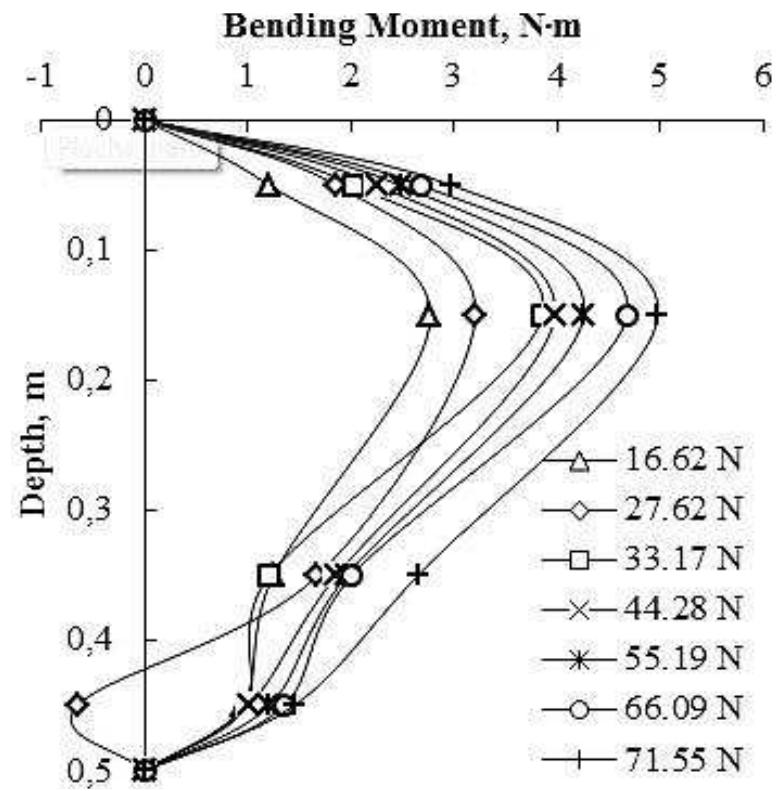

Fig. 5: Bending Moment at horizontal ground. 


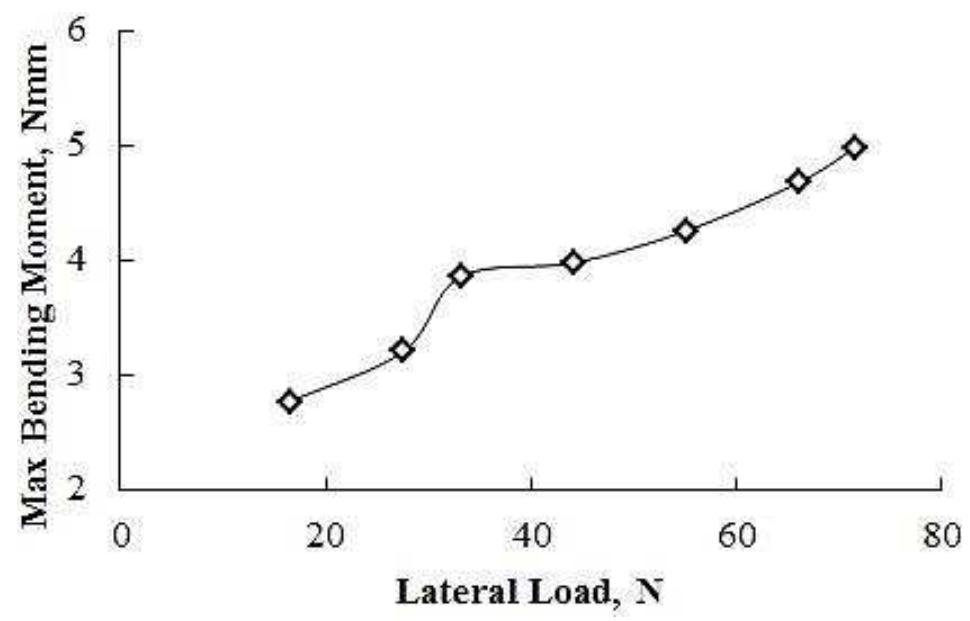

Fig. 6: Lateral load and its corresponding Bending Moment.

Under the horizontal condition for similar loads, the bending moment increases with the increase in eccentricity (Fig. 7a). For an applied load of $33.17 \mathrm{~N}$, the bending moment was observed as 3.86 and $13.641 \mathrm{~N} \cdot \mathrm{mm}$ for an eccentricity of $0 \mathrm{~T}-0 \mathrm{~mm}$ and $0.5 \mathrm{~T}-46 \mathrm{~mm}$. The depth of the maximum bending moment was observed as $0.15 \mathrm{~m}$ from the top of the pile head from where the load was applied; it was also noted as 0.3 times the length of the pile or 1.63 times the stiffness of the pile. But for the pile, where the pile head placed was placed $1 \mathrm{~T}-92 \mathrm{~mm}$ above the ground the bending moment increased to $28.25 \mathrm{~N} \cdot \mathrm{mm}$ with a depth of maximum moment as $0.07 \mathrm{~m}$. This depth was calculated as 0.14 times the length of the pile or 0.76 times the stiffness factor. From Fig. $7 \mathrm{~b}$ it is clearly visible that the bending moment increases linearly with an increase in eccentricity.

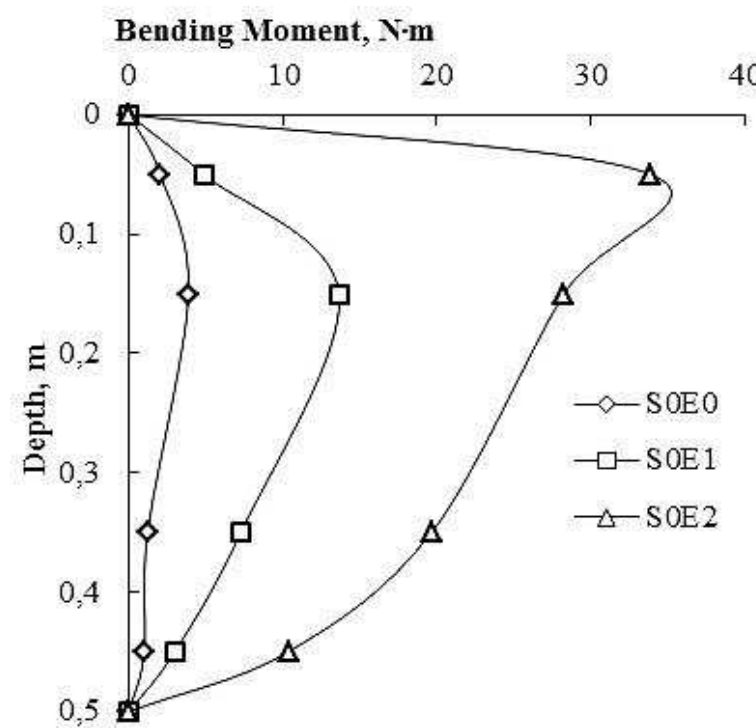

a/ Bending Moment Behaviour

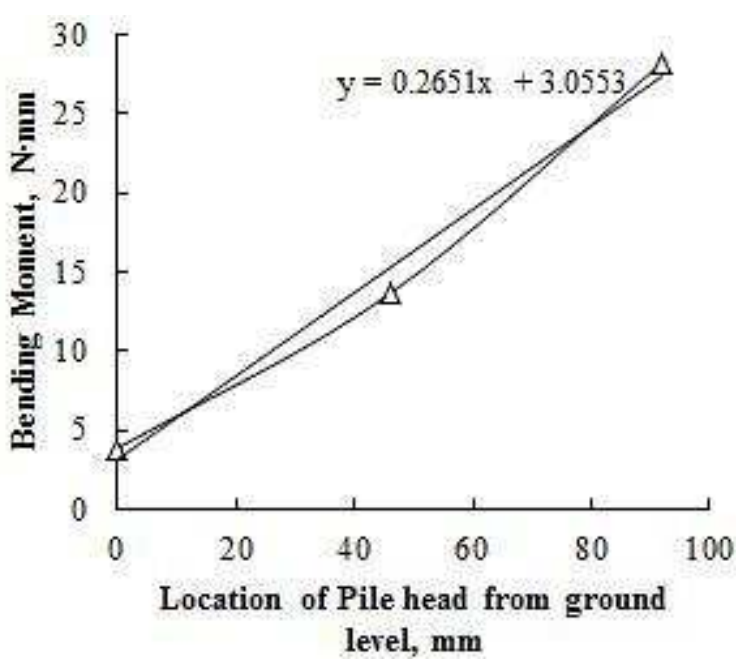

b/ Maximum Bending Moment

Fig. 7: Bending Moment various eccentricity in horizontal ground.

For sloping ground, the bending behaviour of the pile with an increase in loading shows similar behaviour to the behaviour of the pile in the horizontal ground. For a load of $33.17 \mathrm{~N}$, the bending moment in the sloping ground with no free length was observed as $4.12 \mathrm{~N}$ which is $6.74 \%$ higher compared to horizontal ground. But the depth of maximum bending moment varies; for the smaller load, it was observed at a shallow depth $(0.05 \mathrm{~m})$, with an increase in load it had shifted to $0.15 \mathrm{~m}$ of length for S1E0 condition (Fig. 8).

While comparing the bending moment for different eccentricity (Fig. 9a and 9b), the bending moment increased with an increase in free length for the same load under the same slope $(1 \mathrm{~V}: 2 \mathrm{H})$. Similar to the horizontal ground condition, in the sloping ground, there was a linear increase in 
bending moment upon an increase in the eccentricity of the pile. But the slope had shown an increase by 1.11 times the bending moment compared to horizontal ground.

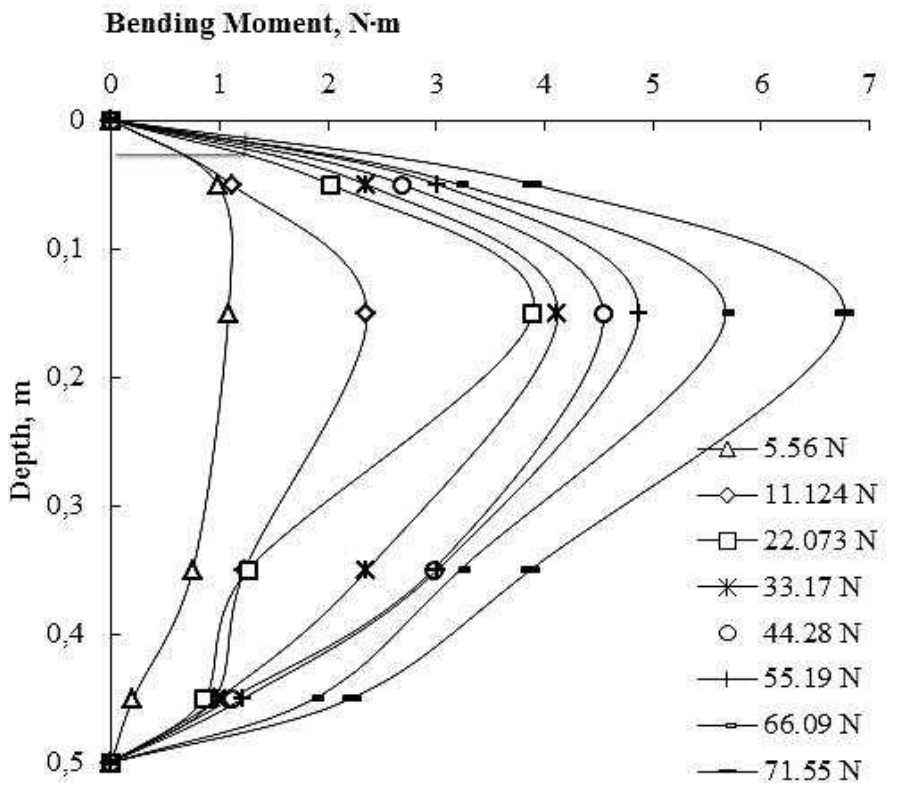

Fig. 8: Bending Moment for a various load for sloping ground where the pile was kept at ground level.

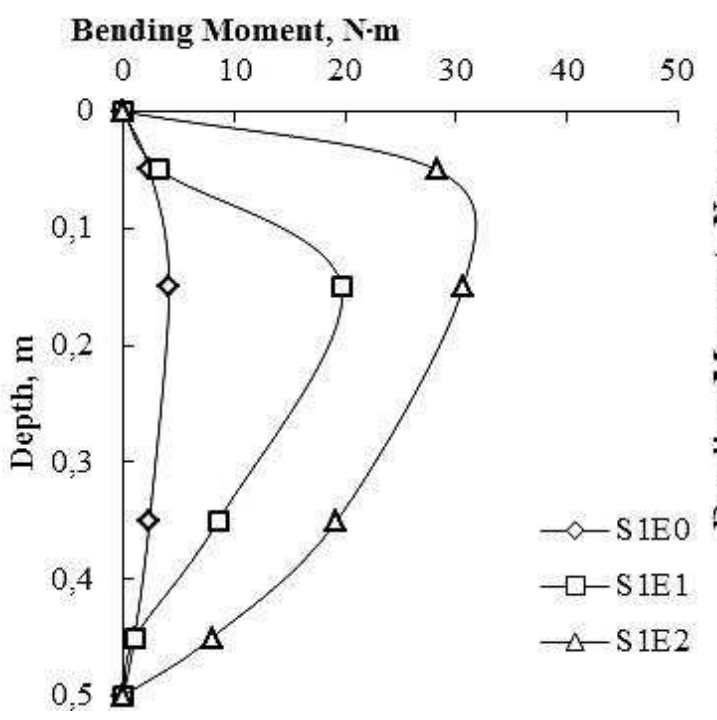

a/ Bending Moment Behaviour

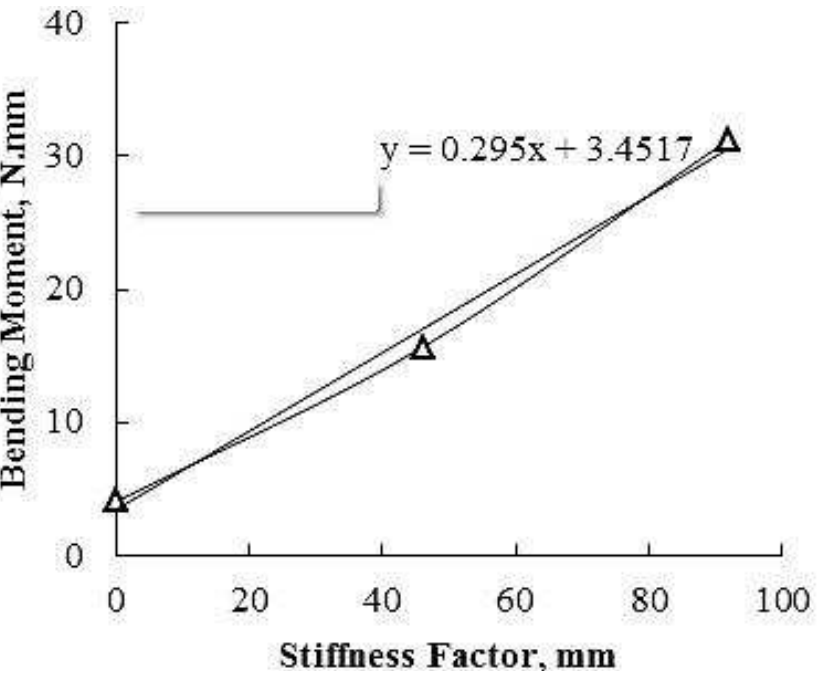

b/ Maximum Bending Moment

Fig. 9: Bending Moment various eccentricity in sloping ground.

The depth of maximum bending moment was also observed similar for both the conditions. For OT and 0.5T of eccentricity, the depth at which maximum bending moment was observed as $0.15 \mathrm{~m}$ and for $1 \mathrm{~T}$ it was observed as $0.07 \mathrm{~m}$.

An equation was edged to calculate the maximum bending moment for a slope of $1 \mathrm{~V}: 2 \mathrm{H}$ from a horizontal ground bending moment equation 2. The same was plotted in figure 10, which showed a linear trend line. With this equation, the maximum bending can be calculated for any calculated eccentricity (which is the stiffness factor in the current study) for a slope of $1 \mathrm{~V}: 2 \mathrm{H}$ using the chart. For lower eccentricity, the obtained equation matches well with the obtained results; this was clearly shown as a dark dotted line in the graph

$y=1.11(0.2651 x+3.0553)$,

where $y$ is the maximum moment and $x$ is the stiffness factor. 


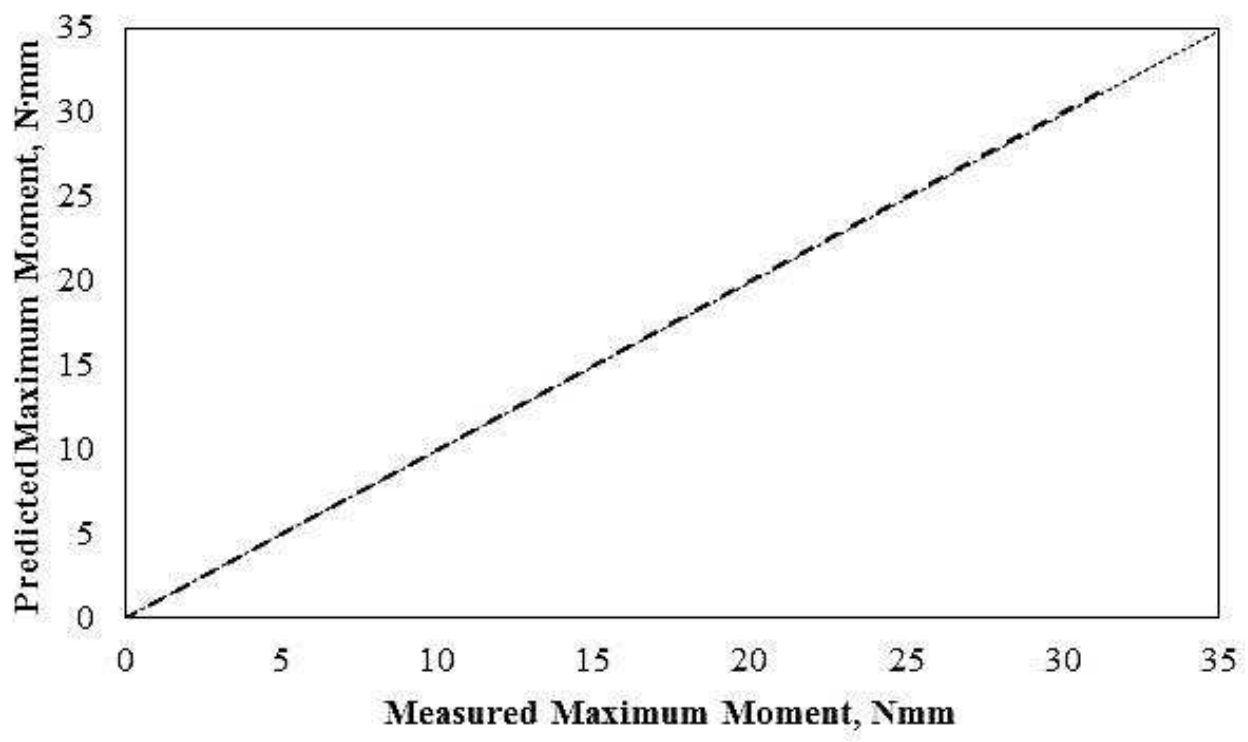

Fig. 10: Predicted vs Measured Maximum bending moment.

For a long flexible pile, the influence of lateral load reduces beyond maximum bending moment; this occurs generally in the top soil layer. However, stiffness factor is calculated based on the soilstructure interaction behaviour which includes the stratified soil.

The main limitations of the developed equation and the graph were restricted to a slope of $1 \mathrm{~V}: 2 \mathrm{H}$. Further studies were suggested to extend the study to the various slope and stratified soil.

\section{Conclusion}

A series of experiment was carried to study the behaviour of the pile in horizontal ground and ground slope of $1 \mathrm{~V}: 2 \mathrm{H}$ in cohesionless soil for various eccentricity kept with respect stiffness factor. The lateral load corresponding to $20 \%$ displacement was considered as an ultimate lateral load. The following conclusions were arrived,

1. For horizontal ground, the maximum lateral load was observed as $6.19 \mathrm{~N}$ and there was a reduction in capacity due to the increase in the eccentricity by 35.86 and $38.93 \%$ for $0.5 \mathrm{~T}$ and $1 \mathrm{~T}$ respectively. The main reason behind the reduction in capacity was due to depth of embedded of the pile. With a reduction in depth of embedment, the rigidity of the pile decreases leading to decrease in lateral load capacity.

2. In sloping ground, the lateral capacity of pile at the crest of the slope was observed as 4.472 , 3.381 and $2.816 \mathrm{~N}$ with no eccentricity, $0.5 \mathrm{~T}$ and $1 \mathrm{~T}$ respectively. With the increase in eccentricity, the lateral capacity decreases linearly when compared to that of the horizontal ground. The reduction in capacity of pile in sloping ground is high which is mainly due to the embedded depth and the reduction in passive wedge, which offers resistance to the pile.

3. With the increase in load, the bending moment of the pile increases. In horizontal ground, the maximum bending moment was observed for pile at $1 \mathrm{~T}$ eccentricity which occurred at a depth of $0.07 \mathrm{~m}$ from the pile head. But the depth of maximum bending moment was $0.15 \mathrm{~m}$ from the pile head for $0 \mathrm{~T}$ and $0.5 \mathrm{~T}$ eccentricity. The similar trend was observed in pile in sloping ground.

4. An equation is arrived for finding the maximum bending moment for pile with various stiffness factor as eccentricity.

\section{References}

[1] POULOS, H. G. - CHEN, L. T. - HULI, T. S.: Model Tests on Single Piles Subjected to Lateral Soil Movement. Soils Found. Japanese Geotech. Soc., Vol. 35, No. 4, 1995, pp. 85-92.

[2] MEYER, B. J. - REESE, L. C.: Analysis of Single Piles Under Lateral Loading. State Department of Highways and Public Transportation, Texas, 1979.

[3] GILL, H .L. - DEMARS, K. R.: Technical Report: Displacement of laterally loaded structures in nonlinearly responsive soil. Naval Civil Engineering Laboratory, California, 1970. 
[4] RUIGROK, J. A. T.: Laterally Loaded Piles: Models and Measurements. Department of Hydraulic Engineering, TU Delft, 2010.

[5] ASHFORD, S. A. - JUIRNARONGRIT, T.: Evaluation of Pile Diameter Effect on Initial Modulus of Subgrade Reaction. J. Geotech. Geoenvironmental Eng., Vol. 129, No. 3, 2003, pp. 234-242.

[6] M. R. - FLEMING, K. E. K. - WELTMAN, A.: Piling Engineering, 3rd ed., Taylor and Francis Group, 1992.

[7] ZHANG, L. - SILVA, F. - GRISMALA, R.: Ultimate Lateral Resistance to Piles in Cohesionless Soils. October, J. Geotech. Geoenvironmental Eng., Vol. 131, January, 2005, pp. 78-83.

[8] DEENDAYAL, R. - MUTHUKKUMARAN, K. - SITHARAM, T. G.: Behaviour of Laterally Loaded 1-g Single Model Pile in Soft Clay with Sloping Ground. 19th International conference on soil mechanics and geotechnical engineering, No. 1, 1998, pp. 915-918.

[9] GEORGIADIS, K. - GEORGIADIS, M.: Computers and geotechnics development of $p-y$ curves for undrained response of piles near slopes. Comput. Geotech., Vol. 40, 2012, pp. 53-61.

[10] CHANDALURI, V. K. - SAWANT, V. A.: Effect of Slope Angle on Pile Response. Indian J. Sci. Technol., Vol. 9, December, 2016, pp. 1-6.

[11] BEGUM, N. A. - MUTHUKKUMARAN, K.: Experimental investigation on single model pile in sloping ground under lateral load. Int. J. Geotech. Eng., 2009, pp. 133-146.

[12] MUTHUKKUMARAN, K.: Effect of sloping ground on single pile load deflection behaviour under lateral soil movement. 13th World Conf. Earthq. Eng., Vo. 2147, 2004, pp. 1-4.

[13] SAWWAF, M.: Lateral resistance of single pile located near geosynthetic reinforced slope. J. Geotech. Geoenvironmental Eng., Vol. 132, No. 10, 2006, pp. 1336-1345.

[14] VERHOEF, R. M.: Laterally loaded piles in sloping ground. Department of Civil Engineering, TU Delft, 2015.

[15] Bureau of Indian Standards, IS 2720(Part III/2) Determination of Specific Gravity for fine, medium and coarse grained soil, Vol. 2720, 1997, pp. 1-10.

[16] Bureau of Indian Standard, IS 2720 (Part IV) Grain size analysis. 1995, pp. 1-40.

[17] Central Bureau of Indian Standards, IS 2720 - XIV (Reaffirmed 2006), No. 1., 1983, pp. 1-16.

[18] Central Bureau of Indian Standards, IS 2720 - XIII (Reaffirmed 2002). 1986, pp. 1-17.

[19] SIVAPRIYA, S. V. - RAMANATHAN, R.: Load - Displacement Behaviour of a Pile on a Sloping Ground for Various L/D Ratios. Slovak J. Civ. Eng., Vol. 27, No. 1, 2019, pp. 1-6.

[20] BROMS, B. B.: Lateral Resistance of Piles in cohesionless soils. J. Soil Mech. Found. Divsion, Vol. SM 3, 1964, pp. 123-156.

[21] Bureau of Indian Standard Code, Indian standards, 2911 (Part 4), Vol. 1, No. 1., 1985, pp. 1-21. 